\title{
How Safe Is Conversion from Tacrolimus to Its Generic Drug?-A Single Center Experience
}

\author{
Tobias A. Marsen \\ Nephrology Center and KfH Kidney and Dialysis Center Köln-Lindenthal, Köln, Germany \\ Email: tobias.marsen@kfh-dialyse.de
}

Received September 25, 2012; revised October 31, 2012; accepted November 7, 2012

\begin{abstract}
Background: Generically produced cyclosporine has long been approved in the treatment of organ transplant recipients and several publications have dealt with its use. For tacrolimus, however, very few data exist for safety and efficacy after conversion to its generic in kidney transplant recipients. Methods: In this single-center observational study, 14 kidney transplant carriers were converted to generic tacrolimus as part of aftercare, and graft function, fasting tacrolimus levels and the daily tacrolimus dose was pursued for up to 95 weeks. Results: Average drug doses changed from $3.64 \pm 1.88 \mathrm{mg} /$ day with the original to $3.33 \pm 1.72 \mathrm{mg} /$ day after conversion to generic tacrolimus $(\mathrm{p}=0.33)$. Tacrolimus fasting levels were $6.23 \pm 1.68 \mathrm{ng} / \mathrm{ml}$ before and $5.89 \pm 1.15 \mathrm{ng} / \mathrm{ml}$ after conversion $(\mathrm{p}=0.66)$. Average serum creatinine values of $2.26 \pm 1.08 \mathrm{mg} / \mathrm{dl}$ after conversion did not differ from previous values of $1.99 \pm 0.74 \mathrm{mg} / \mathrm{dl}$ $(p=0.15)$. Conclusions: These data support the assumption, that it is safe to convert stable kidney transplant patients from the original galenic formulation under close scrutiny to the generically produced substance. Conversion is easy to be implemented in the routine follow-up and thus represents an option in the therapy with calcineurin inhibitors, which will contribute to cost reduction in the health system.
\end{abstract}

Keywords: Kidney; Pharmacoeconomics; Tacrolimus; Transplantation

\section{Introduction}

Calcineurin inhibitors (CNI) cyclosporine and tacrolimus are milestones in the therapy of organ transplantation. They are the basic immunosuppressants in rejection prophylaxis. Under their use, patient as well as graft survival could be significantly improved.

The lifelong therapy however makes this treatment a most cost-intensive requirement. Upon the expiration of patent protection in 1995 a strong generic market grew for cyclosporine and since 2009 for tacrolimus. Despite all security concerns for generic cyclosporine, its use in the follow-up treatment of organ recipients has been regulated by experts [1] and in many centers now has become the rule. Increasing rates of rejection episodes have not been described [2-4].

Since 2009, tacrolimus, because no longer protected by patents, has been made available as a generic formulation for clinical use, too. Under the increasing pressure on costs in the health system in industrial nations, in Germany by the health insurers and by discounting contracts, there is a growing uncertainty concerning the safety of prescribing generic tacrolimus. To document a practical approach in the use of generically produced tacrolimus, as well as to the diverse needs of all parties to meet and generate no disadvantages for graft survival, 14 stable kidney transplant recipients were followed in a single center cohort study after a shift in favor of a tacrolimus generic. Efficacy and safety parameters for graft function and immunosuppression were obtained.

\section{Subjects and Methods}

In this single-center observational study we identified 14 patients, 9 male and 5 female with a functioning kidney transplant and a stable graft function under an immunosuppressive therapy with tacrolimus (Prograf ${ }^{\circledR}$, Astellas Pharma GmbH, Munich, Germany ${ }^{1}$ ). The mean patient age was $51 \pm 16.5$ years and the time after transplantation varied from 12 - 138 months, with a mean of 63 months. The patients were switched as part of their routine follow-up care in the nephrologic center in a 1:1 fashion to an equivalent dose of generic tacrolimus (Tacrolimus $\operatorname{Hexal}^{\circledR}$, Hexal AG, Holzkirchen, Germany ${ }^{2}$ ) as a commercial medication and tracked continuously for 29 - 95

\footnotetext{
${ }^{1}$ Prograf ${ }^{\circledR}$ composition: Tacrolimus-1- $\mathrm{H}_{2} \mathrm{O}$, Methylhydroxypropylcellulose, Lactose-1- $\mathrm{H}_{2} \mathrm{O}$, Croscarmellose-sodium, Mg-Stearate, Gelatine, Titandioxide, Fe-(III)oxide, Phospholipids.

${ }^{2}$ Tacrolimus Hexal ${ }^{\circledR}$ composition: Tacrolimus-1- $\mathrm{H}_{2} \mathrm{O}$, Methylhydroxypropylcellulose, Lactose-1- $\mathrm{H}_{2} \mathrm{O}$, Croscarmellose-sodium, Mg-Stearate, Gelatine, Titandioxide, Na-dodecylsulfate, Sorbitan laurate, Fe-oxide-hydrate.
} 
weeks (mean $66.4 \pm 19.4$ weeks). For safety reasons, controls were performed at weekly intervals initially after conversion and were subsequently extended to monthly and to quarterly controls. Longitudinal comparative data were collected for the trough levels of the immunosuppressant prior to and after conversion, as well as for excretory graft function. Routinely clinical data and blood samples were collected after switching and the tacrolimus dose was adapted as necessary. The following routine laboratory parameters were captured: endogenous creatinine clearance, serum creatinine, tacrolimus trough levels (Abbott tacrolimus assay), blood count, differential blood count, absolute lymphocyte number, $\mathrm{Na}$ (sodium), $\mathrm{K}$ (potassium), $\mathrm{Ca}$ (calcium), $\mathrm{PO}_{4}$ (phosphate), BUN (blood urea nitrogen), uric acid, ALT (alanine aminotransferase), GGT (gamma-glutamyl transpeptidase), AP (alkaline phosphatase), LDH (lactate dehydrogenase), albumin/creatinine ratio, CRP (C-reactive protein), urine sediment (analyzed semi-automatically via urine stix).

\section{Statistical Analysis}

To analyze significant changes in tacrolimus trough levels, tacrolimus doses, and serum creatinine values before and after conversion, student paired t-test was used. The level of significance was set to $\mathrm{p}<0.05$. Results are presented as mean \pm standard deviation.

\section{Results}

14 patients ( 9 male, 5 female) at the age of 25 to 75 years, with a mean of $51 \pm 16.5$ years, after local ethics votum and informed consent was obtained, were converted to generically manufactured Tacrolimus Hexal ${ }^{\circledR}$ (Table 1). This drug is shown to be bioequivalent to the original drug Prograf ${ }^{\circledR}$ in cross-over studies [5]. At the time of conversion, the patients had a functioning-kidney transplant between 12 to 138 months, with a mean of 63 months. The transplant kidney function was stable at the time of conversion in 13 patients, a male patient was confirmed 41 months previously with biopsy proven chronic allograft rejection, which prompted his conversion to Prograf $^{\circledR}$. Despite conversion he had a continuous decrease in graft function, serum creatinine had increased from 3.7 to $4.2 \mathrm{mg} / \mathrm{dl}$ during run-in. Furthermore, a female patient was 36 month prior to conversion also confirmed with biopsy proven chronic-allograft rejection, but during run-in had a much less accelerated course with serum creatinine from 2.55 to $2.6 \mathrm{mg} / \mathrm{dl}$.

Among all patients 10 out of 14 had a concomitant immunosuppression therapy with steroids, 11 out of 14 received mycophenolate mofetil, either MMF (500 - 2000 $\mathrm{mg} /$ day) or MMF-sodium (360 - $1440 \mathrm{mg}$ /day), 2 out of 14 were on azathioprine. 5 out of 14 patients were on a dual immunosuppression. During the observation phase the concomitant immunosuppression was not altered in the dose or the choice of preparations. All patients suffered from stable arterial hypertension as concomitant disease, and 4 had NIDDM/IDDM.

After conversion, generic tacrolimus was well tolerated in all patients, there were no symptoms of intolerance, safety laboratory parameters remained unchanged. The average drug doses (Figure 1) and tacrolimus levels (Figure 2) before and after conversion were not significantly different from each other in the longitudinal course (Table

Table 1. Patients individual demographic characteristics (Mean values represent average data for periods "run-in pre conversion" and "follow up after conversion").

\begin{tabular}{|c|c|c|c|c|c|c|c|}
\hline Sex & Age (years) & $\begin{array}{c}\text { Time since TX } \\
\text { (month) }\end{array}$ & $\begin{array}{c}\text { Run-in } \\
\text { pre conversion } \\
\text { (weeks) }\end{array}$ & $\begin{array}{l}\text { Follow-up } \\
\text { after } \\
\text { conversion } \\
\text { (weeks) }\end{array}$ & $\begin{array}{c}\text { Mean Tac } \\
\text { trough level } \\
\text { (ng/ml) Post/ } \\
\text { pre conversion }\end{array}$ & $\begin{array}{l}\text { Mean Tac dose } \\
\text { (mg/day) Post/ } \\
\text { pre conversion }\end{array}$ & $\begin{array}{c}\text { Mean } \\
\text { creatinine } \\
(\mathrm{mg} / \mathrm{dl}) \\
\text { Post/ } \\
\text { pre conversion }\end{array}$ \\
\hline Male & 45 & 25 & 61 & 79 & $5.95 / 5.9$ & $2.0 / 2.6$ & $1.25 / 1.21$ \\
\hline Male & 63 & 29 & 65 & 67 & 6.92/8.38 & $3.2 / 4.0$ & $1.70 / 1.86$ \\
\hline Female & 72 & 88 & 64 & 95 & $5.19 / 6.66$ & $4.0 / 4.0$ & $1.24 / 1.35$ \\
\hline Male & 31 & 136 & 76 & 75 & $4.50 / 6.00$ & 3.0/3.0 & $1.98 / 2.07$ \\
\hline Female & 68 & 39 & 76 & 48 & $5.75 / 5.92$ & $4.0 / 6.0$ & $1.10 / 1.08$ \\
\hline Female & 75 & 56 & 64 & 61 & $6.20 / 6.62$ & $2.0 / 2.0$ & $1.45 / 1.53$ \\
\hline Female $^{\mathrm{a}}$ & 63 & 138 & 76 & 51 & $7.07 / 5.10$ & $2.67 / 2.0$ & $3.47 / 2.30$ \\
\hline Female & 43 & 90 & 29 & 79 & 7.66/7.53 & $5.0 / 5.3$ & $3.49 / 2.46$ \\
\hline Male & 25 & 76 & 66 & 80 & $3.12 / 5.68$ & $3.5 / 2.7$ & $2.21 / 2.12$ \\
\hline Male & 55 & 18 & 68 & 29 & $5.40 / 5.41$ & 7.0/8.4 & $2.75 / 2.54$ \\
\hline Male $^{\mathrm{a}}$ & 42 & 92 & 76 & 77 & $5.38 / 4.56$ & $4.0 / 3.0$ & $5.48 / 3.78$ \\
\hline Male & 33 & 37 & 47 & 35 & $8.03 / 6.35$ & 2.3/1.0 & $1.65 / 1.70$ \\
\hline Male & 39 & 12 & 46 & 68 & $5.78 / 6.41$ & $3.0 / 3.7$ & $1.56 / 1.50$ \\
\hline
\end{tabular}

apatients have biopsy proven chronic allograft rejection. 
2). Also, the mean serum creatinine levels did not differ from the previous values and remained stable over the study period (Figure 3).
During the entire observation period dose-adjustments had to be performed with both the originator or generic Tacrolimus Hexal $^{\circledR}$ in 6 out of 14 cases downwards and

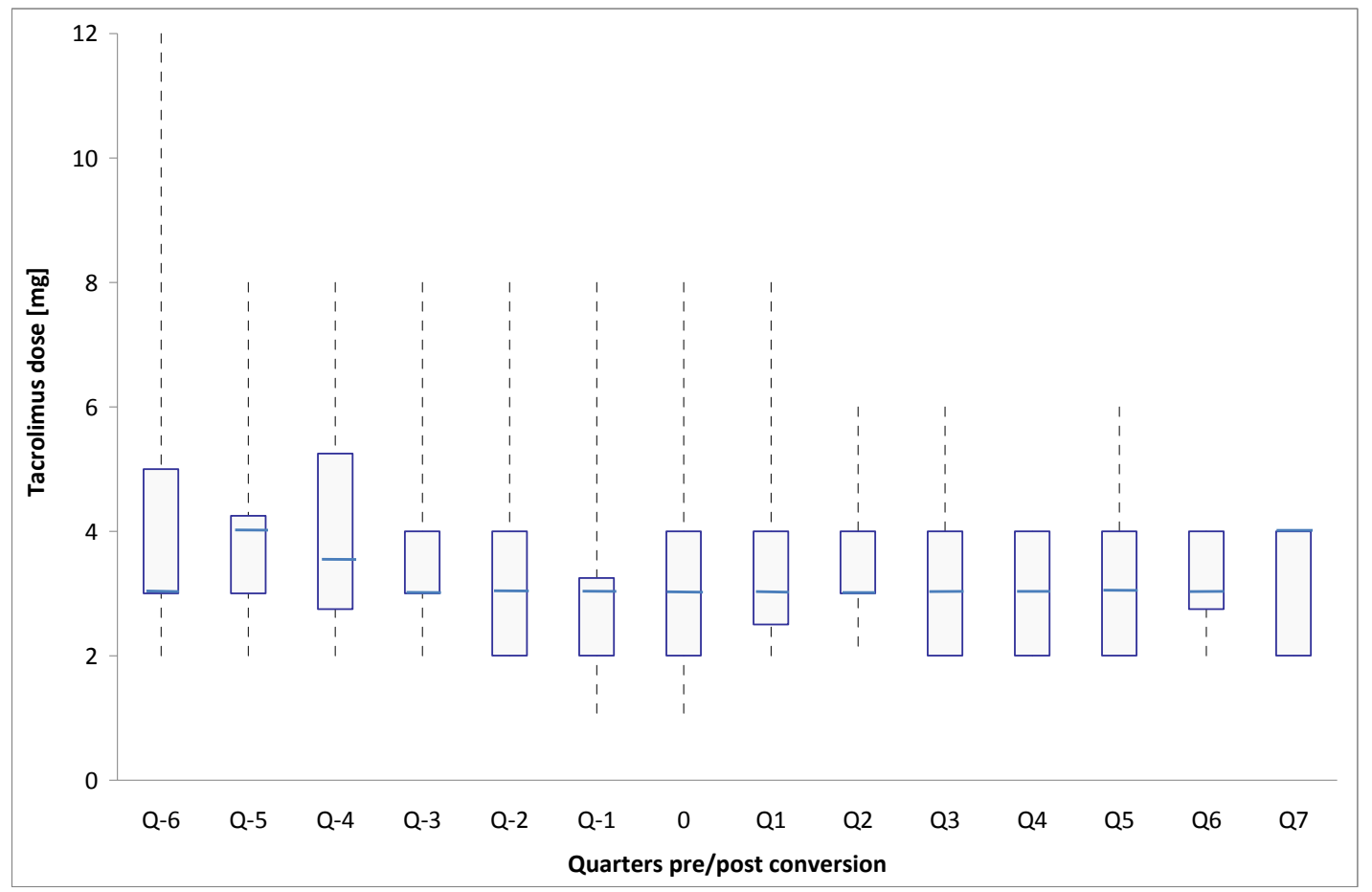

Figure 1. Box-Whisker-plot of tacrolimus daily dose followed 6 quarters before $(Q-x)$ and 7 quarters after $(Q \mathbf{x})$ generic tacrolimus conversion (each quarter represents sampling of 10 patients on average $\left(n_{\max }=13, n_{\min }=6\right.$ ), time of conversion is outlined as 0 ).

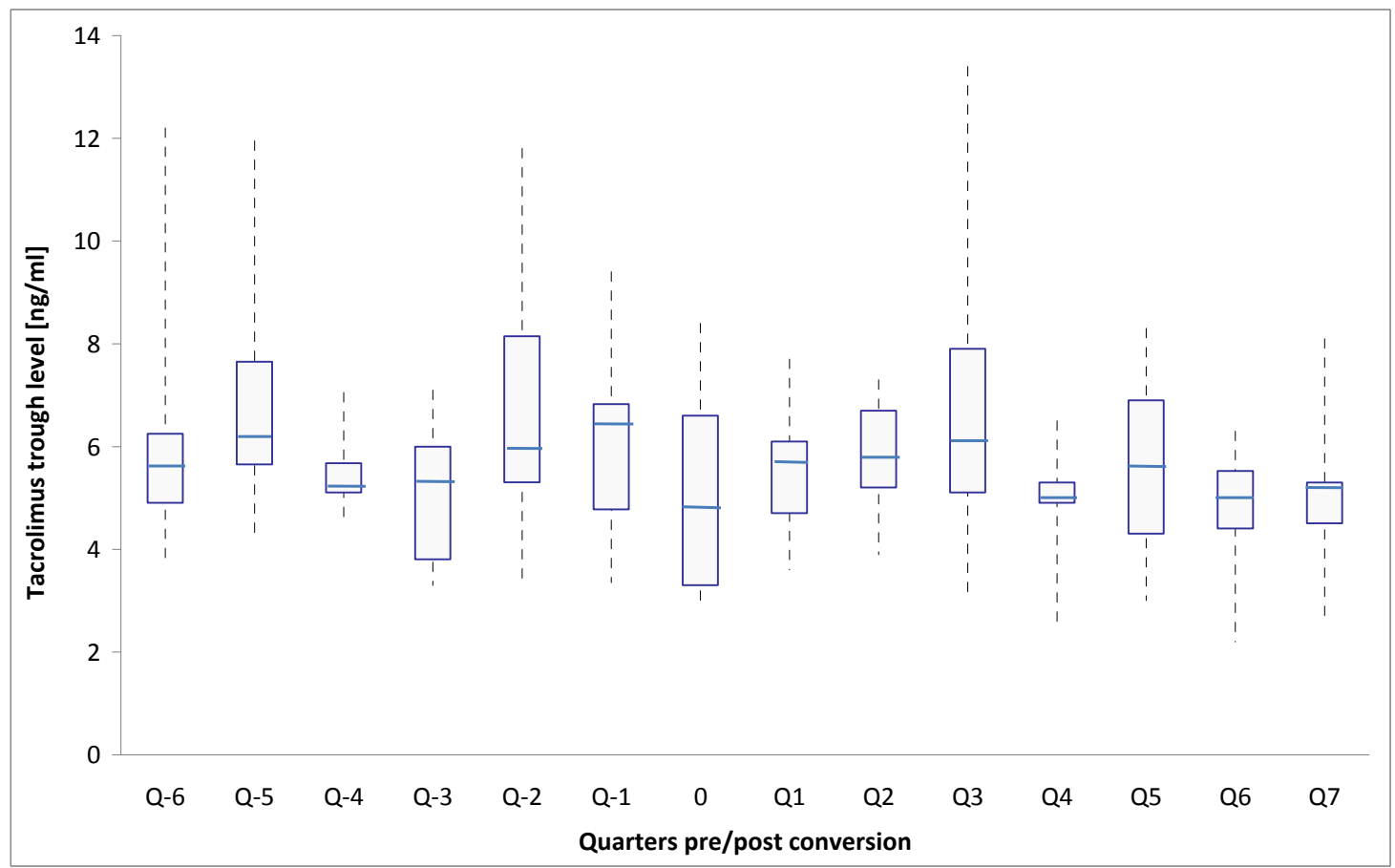

Figure 2. Box-Whisker-plot of mean tacrolimus trough levels of 14 kidney transplant recipients followed 6 quarters before (Q - $\mathbf{x})$ and 7 quarters after $(\mathbf{Q})$ generic tacrolimus conversion (time of conversion is outlined as 0 ). 


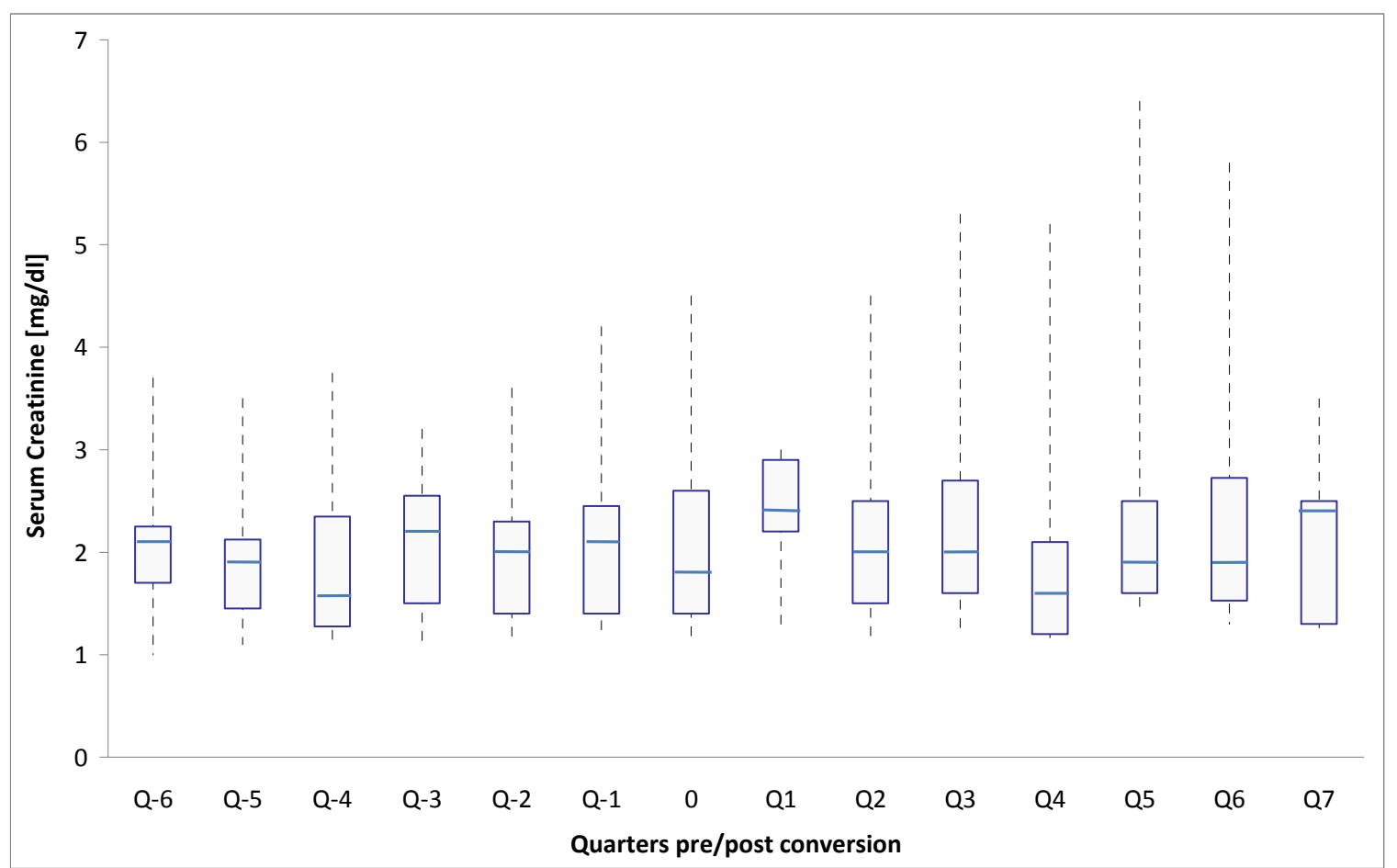

Figure 3. Box-Whisker-plot of mean creatinine levels of 14 maintenance kidney transplant recipients 6 quarters before (Q - x) and 7 quarters after $(Q x)$ generic tacrolimus conversion (each quarter represents sampling of 10 patients on average $\left(n_{\text {max }}=\right.$ $13, n_{\min }=6$ ), time of conversion is outlined as 0 ).

Table 2. Mean treatment specific patient characteristics (mean \pm standard deviation). Mean values represent average data for period length as given in table $1^{\mathrm{a}}$.

\begin{tabular}{|c|c|c|c|c|}
\hline & $\begin{array}{l}\text { Mean Tac trough } \\
\text { level }[\mathrm{ng} / \mathrm{ml}]\end{array}$ & $\begin{array}{c}\text { Mean Tac } \\
\text { dose [mg/day] }\end{array}$ & $\begin{array}{l}\text { Mean creatinine [mg/dl] } \\
\text { all patients }^{\mathrm{a}}\end{array}$ & $\begin{array}{c}\text { Mean creatinine }[\mathrm{mg} / \mathrm{dl}] \\
\text { patients with stable function }\end{array}$ \\
\hline $\begin{array}{c}\text { Pre conversion [weeks] } \\
63.29 \pm 13.87\end{array}$ & $6.23 \pm 1.68$ & $3.64 \pm 1.88$ & $1.99 \pm 0.74$ & $1.80 \pm 0.47$ \\
\hline $\begin{array}{c}\text { Post conversion [weeks] } \\
66.43 \pm 19.38\end{array}$ & $5.90 \pm 1.15$ & $3.33 \pm 1.72$ & $2.26 \pm 1.08$ & $1.89 \pm 0.70$ \\
\hline p-Value & 0.64 & 0.33 & 0.15 & 0.39 \\
\hline
\end{tabular}

a patients with biopsy proven chronic allograft rejection included..

in 4 out of 14 upwards, in order to keep blood levels steady. After conversion no immediate dose-adjustments were necessary, however as early as week 9 a single case required a $1 \mathrm{mg}$ daily increase. 4 patients required late dose-adjustments after week 14 - 17, both downwards and upwards, which have to be refered to as the usual titrations under therapy. According to our data, however, post conversion daily doses showed more stable course as pre conversion doses did, with less variation (Figure 3).

The excretory kidney function and all safety parameters remained stable without significant deviations compared to previously documented values. Of all patients converted, two individuals showed a continuous increase in serum creatinine levels due to a preceeding bi- opsy-confirmed chronic allograft rejection.

\section{Discussion}

The aim of the present study was to demonstrate the safety and efficacy of conversion to generic tacrolimus in stable kidney transplant patients, it was not the aim of the study to generate AUC comparisons, which were generated elsewhere [5]. Moreover, in the context of this cohort study, a practical modality for a change of this critical drug was to be delineated, which could be inserted easily into clinical praoctice, assuring a straight-forward application and a high therapeutic safety.

Critical-dose drugs are known as medications which are controlled via blood levels and in this regard have a 
narrow therapeutic corridor. Changes in drug preparations should ideally lead only to minor differences in blood levels, so as not to interrupt or decrease drug availability and to flare up the disease to be treated in a critical way. With calcineurin inhibitors (CNI) including tacrolimus, this would ultimately result in an impaired immune suppression and trigger organ rejection episodes. According to KDIGO guidelines for cost reduction, generic treatment of kidney transplant recipients may be admitted, if safety and efficacy could be demonstrated [6, 7]. However, conversions should be implemented by an expert in the handling and control of these therapies.

In only a single report, data for the early controlled conversion in liver and kidney transplant carriers have been documented and demonstrated the bioequivalence in clinical use [8]. The short follow-up period but especially the vigilant therapeutic drug monitoring process in this early post-transplant phase triggered critical discussion, leading to remarks on whether "we are jeopardizing our patients health if we do not perform vigilant therapeutic drug monitoring” during conversion [9]. In contrast the present study on late tacrolimus conversion could easily be integrated into the continuous ambulatory treatment of stable transplant patients and be accomplished. Drug monitoring was performed as usual without jeopardization of transplant survival or the patient's health. There were no reports of compatibility problems. Within 1 - 4 weeks after conversion, security parameters collected for therapeutic safety did not deviate significantly from the previously documented data, as well as the long-term follow-up in 12 of 14 patients revealed no change of graft function. Two patients with biopsyproven chronic allograft rejection, however, showed a progressive decrease in graft function similar to the runin phase before the conversion. In these patients, neither the originator nor the generic tacrolimus formulation had made a contribution to achieve a stabilized kidney function.

Despite close supervision, not before week 9 dose adjustment of generically manufactured tacrolimus was required. The probability of occurrence of this behavior is similar to the observation period before conversion, during which only 1 patient had to be reduced in dose. Further 4 patients required late adjustments on weeks 14 - 17, and could be continued without further adjustments thereafter, they may be referred to as usual dose fluctuations. The remaining patients were unchanged and doseequivalent to the time prior to conversion. All adjustments were made on the basis of fasting blood levels for tacrolimus.

The present findings provide no data on the potential savings of total costs in this population. In a comparison between cyclosporine formulations it has been demonstrated, that, when using the generic, de novo transplant recipients revealed significantly higher total costs for the health system, resulting from the required dose escalation [10]. In contrast, conversion to tacrolimus generic in subjects 70 month after transplantation allows for savings [11]. Rising costs of treatment are primarily generated in the first 2 years after transplantation [12]. They result mainly from rejections, viral infections and delayed graft function with dialysis requirements. After this period, the cost of immunosuppressive therapy come to the fore, and comprise a majority. As shown in the present study, the switch in favor of a generic CNI, assuming a situation with stable graft function and a time point as early as 2 years after transplantation, therefore may provide the possibility of cost reduction by optimizing the cost-intensive continuous immunosuppression.

The study has certain limitations. Designed as an observational study in outpatients, adherence could not be directly validated. Also, the sample size was relatively small. Therefore, the results need to be confirmed in a larger, controlled, prospective trial.

In summary, conversion from original to generic tacrolimus is a straightforward procedure in the follow-up of a stable set of kidney transplant carriers, which in the hands of a skilled and in control of these therapies experienced clinician, can be included easily into clinical practice as part of routine follow-up examinations. It meets the health insurance requirements of cost-efficiant maintenance therapy for graft survival. Furthermore, it puts the after-care nephrologist in a position to implement the relevant budget requirements without disadvantages in the treatment needs and safety. In the future, it may be expected, that the share of generic tacrolimus will grow in size and percentage and catch up with the frequency of the original prescription drug or may overtake it.

\section{Conclusion}

In renal transplant carriers, stably treated with Prograf ${ }^{\circledR}$, conversion to a generic tacrolimus can be performed in a straight forward manner. Tacrolimus fasting levels, doses employed and transplant function remain stable, without generating episodes of rejection. Cost savings potential can be fulfilled without causing harm to the patient.

\section{Acknowledgements}

The author greatly acknowledges the contribution of Michael Maerz, MCSc, for performing the statistical analysis.

\section{REFERENCES}

[1] S. Pollard, B. Nashan, A. Johnston, P. Hoyer, P. Belitsky, P. Keown and H. Helderman, "A Pharmacokinetic and Clinical Review of the Potential Clinical Impact of Using 
Different Formulations of Cyclosporine A," Clinical Therapeutics, Vol. 25, No. 6, 2003, pp. 1654-1669. doi:10.1016/S0149-2918(03)80161-3

[2] W. Carnahan and T. Y. Cooper, "Neoral to Gengraf Conversion in Renal Transplant Recipients," Transplantation Proceedings, Vol. 35, No. 4, 2003, pp. 1308-1313. doi:10.1016/S0041-1345(03)00423-8

[3] J. S. Al Wakeel, F. A. Shaheen, M. C. Mathew, H. M. Abouzeinab, A. Al Afi, N. M. Tarif, M. S. Mousawi, T. S. Mahmoud, A. S. Alorrayad, E. A. Fagir, R. S. Dham and D. S. Shaker, "Six-month Clinical Outcome of Cyclosporine Microemulsion Formulation (Sigmasporin Microral) in Stable Renal Transplant Patients Previously Maintained on Sandimmun Neoral," Transplantation Proceedings, Vol. 40, No. 7, 2008, pp. 2245-2251. doi:10.1016/j.transproceed.2008.06.044

[4] H. Müller, S. Solari, C. Zuñiga, C. Pedreros, J. Troncoso, C. Morente, R. Ovalle, P. Acosta, T. Chavez and E. Albornoz, "Immunosuppression with Generic Tacrolimus and Mycophenolate Mofetil in Renal Transplant Recipients: Preliminary Report in Chile,” Transplantation Proceedings, Vol. 40, No. 3, 2008, pp. 705-707. doi:10.1016/j.transproceed.2008.02.056

[5] "Public Assessment Report of the Medicines Evaluation Board in the Netherlands". http://db.cbg-meb.n/mri/par/nih-1340-001-002-003.pdf.

[6] T. R. Türk, O. Witzke and M. Zeier, "KDIGO-Leitlinien Zur Betreuung von Nierentransplantatempfängern,” Nephrologe, Vol 5, No. 2, 2010, pp. 94-107. doi:10.1007/s11560-009-0369-6

[7] Kidney Disease: Improving Global Outcomes (KDIGO)
Transplant Work Group, "KDIGO Clinical Practice Guideline for the Care of Kidney Transplant Recipients,” American Journal of Transplantation, Vol. 9, Suppl. 3, 2009, pp. S1-S155. doi:10.1111/j.1600-6143.2009.02834.X

[8] J. D. Momper, T. A. Ridenour, K. S. Schonder, R. Shapiro, A. Humar and R. Venkatarmanan, "The Impact of Conversion from Prograf to Generic Tacrolimus in Liver and Kidney Transplant Recipients with Stable Graft Function,” American Journal of Transplantation, Vol. 11, No. 9, 2011, pp. 1861-1867. doi:10.1111/j.1600-6143.2011.03615.x

[9] G. B. Klintmalm, "Immunosuppression, Generic Drugs and the FDA,” American Journal of Transplantation, Vol. 11, No. 9, 2011, pp. 1765-1766. doi:10.1111/j.1600-6143.2011.03616.x

[10] J. H. Helderman, N. Kang, A. P. Legoretta and J. Y. Chen, "Healthcare Costs in Renal Transplant Recipients Using Branded versus Generic Cyclosporine,” Applied Health Economics and Health Policy, Vol. 8, No. 1, 2010, pp. 61-68.

[11] L. M. McDevitt-Potter, B. Sadaka, E. M. Tichy, C. C. Rogers and S. Gabardi, "A Multicenter Experience with Generic Tacrolimus Conversion,” Transplantation, Vol. 92, No. 6, 2011, pp. 653-657. doi:10.1097/TP.0b013e31822a79ad

[12] E. G. Hagenmeyer, B. Häussler, E. Hempel, G. Grannas, Z. Kaló, A. Kilburg and B. Nashan, "Resource Use and Treatment Costs after Kidney Tranplantation: Impact of Demographic Factors, Comorbidities, and Complications," Transplantation, Vol. 77, No. 1, 2004, pp. 1545-1550. 